\title{
Mitos do amor romántico
}

\section{Romantic love myths}

\author{
Noemí Giráldez Rodríguez, Encarnación Sueiro Domínguez \\ Facultade de Ciencias da Educación (Universidade de Vigo-Campus de Ourense)
}

\begin{abstract}
Resumo
Realizouse unha investigación sobre o Nivel de Aceptación dos Mitos do Amor Romántico en 103 suxeitos, alumnado do Grao en Traballo Social da Universidade de Vigo e a súa relación con diferentes variables (Sociodemográficas, coa existencia de Relación de Parella e coa Autoestima). Os resultados indican unha importante aceptación dos Mitos do Emparellamento e a Fidelidade, con porcentaxes en torno ao 70 e $60 \%$, respectivamente; e un rexeitamento elevado do Mito dos Celos, da Perdurabilidade e da Exclusividade, co 75, 67 e o 53\%, respectivamente. Atopáronse diferenzas significativas $(\mathrm{p}<.05)$ en relación a algúns Mitos e ás variables Sexo e Curso.

Palabras clave: [mitos, amor, mocidade, traballo social]
\end{abstract}

\begin{abstract}
This work was to investigate the Acceptance Level of the Romantic Myths by the Degree in Social Work students of the University of Vigo, in relation to different variables (Socio-demographic, Couple Relations, and Self-esteem); for this, a structured questionnaire was administered to 103 subjects and whose responses were analyzed with SPSSS/19. The results show important acceptance Myths of the Couple and Fidelity. They reach percentages close to the 70 and $60 \%$, respectively. They also show a high rejection of the Jealousy, the Eternal Passion and the Exclusivity Myths, with percentages of 75, 67 and $53 \%$. Significant differences were spotted $(\mathrm{p}<.05)$ connected to some Myths and the variables Sex and Course.

Keywords: myths, love, young people, social work
\end{abstract}

O amor ocupa un lugar moi importante na vida das persoas, sendo un compoñente fundamental da felicidade. Agora ben, tamén pode ser fonte de insatisfacción e desdita, especialmente cando vai ligado aos Mitos do Amor Romántico, que expoñen como normativos modelos de relación de parella inalcanzables e imposibles.

Pero, que é o amor? e os mitos do amor romántico?

Non se pode definir o amor dun xeito categórico, dado o seu carácter abstracto, diverso e amplo. É, ao mesmo tempo, un sentimento universal e unha construción social na que interveñen múltiples dimensións (histórica, biolóxica, socio-cultural e individual) (Castañón, 2012).

Na sociedade occidental prevalece o concepto de Amor Romántico, estreitamente vinculado aos Mitos.
Un mito é unha crenza que se presenta, en termos absolutos e inflexibles, como unha verdade (Ferrer, Bosch e Navarro, 2010). Máis concretamente, os Mitos do Amor Romántico, segundo Yela (2003), son “o conxunto de crenzas socialmente compartidas sobre a suposta verdadeira natureza do amor” (p. 264).

Seguindo as aportacións de Barrón et al. (1999), Yela (2000 e 2003), Bosh et al. (2007) e de Ferrer, Bosch e Navarro (2010), investigáronse os seguintes Mitos:

1. Mito do Emparellamento

Crenza de que a parella é algo natural e universal, polo que en tódalas épocas e culturas o ser humano tendeu por natureza a emparellarse.

2. Mito da Perdurabilidade ou da Paixón Eterna

Crenza de que o Amor Romántico e pasional dos primeiros meses pode e debe perdurar tras miles de días (e noites) de convivencia.

3. Mito da Exclusividade

Crenza de que só se pode sentir amor por unha única persoa, e que, polo tanto, é imposible estar namorado de dúas persoas á vez.

4. Mito da Fidelidade

Crenza de que tódolos desexos pasionais, románticos e eróticos, deben satisfacerse exclusivamente cunha única persoa, a propia parella, se é que se sinte amor verdadeiro.

5. Mito da Equivalencia

Crenza de que os conceptos de amor e namoramento son equivalentes, e polo tanto, que se un/ha deixa de estar apaixonadamente namorado/a é que xa non ama a súa parella. En consecuencia, segundo este Mito, o mellor é deixala relación.

6. Mito da Omnipotencia

Baséase na idea de que o amor todo o pode, que debe permanecer ante todo e sobre todo.

7. Mito da Media Laranxa

Crenza de que a parella elixida xa estaba predestinada de antemán, sendo a mellor e única elección posible.

8. Mito do Matrimonio ou Convivencia

Crenza de que o Amor Romántico-pasional debe conducir á unión estable da parella e constituírse na única base do matrimonio ou da convivencia en parella.

9. Mito dos Celos

Crenza de que os celos son un indicador de verdadeiro amor.

A interiorización destas crenzas pode ter un importante impacto negativo no benestar persoal. A crenza nos mesmos pode dar lugar ao establecemento de relacións negativas e tóxicas e xerar problemas na 
saúde psicosocial das persoas por teren que enfrontarse continuamente a imposicións contraditorias, entre elas e coa propia natureza do ser humano, imposibles de acadar. As consecuencias poden ir dende o desasosego persoal, o desenvolvemento de sentimentos de frustración e decepción ata a discusións e problemas na parella, máis ou menos intensas (Yela, 2000). Agora ben, tamén pode chegar a extremos máis dramáticos, dando lugar a dependencia emocional, desigualdade dentro da parella, violencia, etc (Moral e Sirvent, 2008).

A maiores, baixo estes Mitos subxacen en moitas ocasións a desigualdade entres persoas e a perpetuación dos roles de xénero tradicionais.

Dado o impacto dos Mitos no benestar, cómpre averiguar o nivel de aceptación ou rexeitamento dos mesmos por parte do alumnado de Traballo Social, futuros/as profesionais que deben ser especialmente sensibles ás estruturas sociais subxacentes. Así mesmo, convén coñecer a relación destas crenzas con diferentes variables (Sociodemográficas, coa existencia de Relación de Parella e coa Autoestima). Daquela, os obxectivos desta investigación foron:

1. Obxectivo Xeral

Coñecer o grado de Aceptación dos Mitos do Amor Romántico.

2. Obxectivos Específicos

-Averiguar a relación existente entre a Aceptación dos Mitos do Amor Romántico e as variables sociodemográficas (Sexo e Curso).

- Investigar a relación entre a Aceptación dos Mitos do Amor Romántico e a Existencia dunha Relación de Parella.

-Coñecer a relación existente entre a Aceptación dos Mitos do Amor Romántico e o nivel de Autoestima.

\section{Método}

Trátase dun estudo descritivo, cuantitativo e transversal.

\section{Participantes}

Os suxeitos da investigación son 103 alumnos/as do Grao en Traballo Social da Universidade de Vigo dos cursos de primeiro e cuarto (de 18 a 34 anos). Na seguinte táboa plásmanse os Datos Sociodemográficos. Na segunda recóllense os datos sobre a tenencia pasada ou actual dunha Relación de Parella.

Táboa 1.

Datos sociodemográficos

\begin{tabular}{lll}
\hline Sexo & Mulleres & $86(83,5 \%)$ \\
& Homes & $17(16,5 \%)$ \\
\hline Idade & Media & 22,01 \\
& Desviación típica & 2,79 \\
\hline Curso & Primeiro & $47(45,6 \%)$ \\
& Cuarto & $56(54,4 \%)$ \\
\hline
\end{tabular}

Táboa 2.

Existencia de relación de parella

\begin{tabular}{lll}
\hline Algunha vez & Si & $94(93,1 \%)$ \\
& Non & $9(8,7 \%)$ \\
\hline Actual & Si & $60(58,3 \%)$ \\
& Non & $41(39,8 \%)$ \\
\hline
\end{tabular}

Como podemos comprobar, as mulleres representan o 83,5\% da participación. A idade media das persoas que conforman o estudo está en torno aos 22 anos. Os suxeitos do Cuarto Curso son algúns máis do 50\%.

Unha porcentaxe moi alta, o 91,3\%, declara ter mantido unha Relación de Parella Algunha Vez e actualmente manteñen unha Relación de Parella o $58,3 \%$ da mostra.

\section{Instrumentos}

Realizamos unha enquisa estruturada na que se indagou sobre datos Sociodemográficos, tenencia de Relación de Parella, nivel de Aceptación dos Mitos e nivel de Autoestima.

Para a recolección dos Datos Sociodemográficos realizouse un cuestionario ad hoc con información relativa ao Sexo e ao Curso. As preguntas relativas á tenencia de Relación de Parella proveñen da enquisa do CIS “Actitudes y conductas afectivas de los españoles en el plano afectivo” (1995).

A seguinte parte do cuestionario foi á relativa aos Mitos. Este apartado estaba composto por nove ítems, cada un dos cales consistía nunha frase que facía referencia a un mito. As frases foron extraídas da Enquisa do Centro de Investigacións Sociolóxicas (1995), excepto o ítem relativo ao Mito dos Celos, que foi extraído da investigación de Ferrer, Bosch, Navarro e Ferreiro (2010). O formato das respostas é de tipo Likert, nunha escala de 5 puntos, sendo 1 "moi en desacordo" e 5 “moi de acordo”. Para a análise dos datos agrupáronse as respostas en tres niveis: desacordo, indiferenza e acordo.

A Autoestima mediouse utilizando a escala de valoración de Rosenberg (1965), traducida e validada por Atienza, Balaguer e Moreno (2000). Consta de 10 ítems, cuxas respostas preséntanse en formato tipo Likert, cun rango de 4 puntos que vai dende o 1 "moi en desacordo", ao 4 "moi de acordo". A puntuación total denota o nivel de Autoestima global da persoa, sendo Elevada se o resultado total varía entre 30 e 40 puntos, Media no caso de atoparse entre os 26 e 29 puntos e Baixa cando é inferior aos 25 puntos.

\section{Procedemento}

O cuestionario elaborado a partir dos instrumentos anteriormente descritos, foi aplicado ao alumnado de Primeiro e Cuarto Curso, do Grao en Traballo Social (Campus de Ourense- Universidade de Vigo). Os datos recadados introducíronse no SPSS/19 para realizar as probas estatísticas correspondentes. 
En primeiro lugar, realizouse a análise descritiva das variables incluídas no Cuestionario (frecuencias e porcentaxes), isto é: Sexo, Curso, existencia de Relación de Parella, Mitos Románticos e Autoestima Global. Posteriormente, realizouse a proba X2 co obxectivo de aceptar ou rexeitar a hipótese de relación entre as variables e concluír a existencia ou non de diferenzas significativas (Hernández et al., 2007).

\section{Resultados}

A continuación, os resultados acadados na investigación.

Os Mitos con maior nivel de aceptación son os seguintes:

* do Emparellamento (o 74,7\% mostrouse de acordo co ítem "A parella é algo natural; en tódalas épocas e culturas o ser humano tendeu por natureza a emparellarse").

* da Fidelidade (o 61,2\% mostrouse de acordo co ítem "Se se ama verdadeiramente, se é fiel á parella sempre”).

* do Matrimonio (o 49,5\% mostrouse de acordo co ítem “A xente só debería casarse por amor”).

Por outra banda, os Mitos máis rexeitados son o:

* dos Celos (o 75,7\% mostrouse en desacordo co ítem “Os celos son unha proba de amor”).

* da Perdurabilidade ou Paixón Eterna (o 67,9\% mostrouse en desacordo co ítem "Unha relación amorosa verdadeira debe perdurar toda a vida”).

* da Exclusividade (o 53,4\% mostrouse en desacordo co ítem "Non se pode estar namorado de dúas persoas á vez”).

* da Media Laranxa (o 41,7\% posicionouse en desacordo co ítem "Cando se trata de relacións de parella, creo que existe alguén que dalgunha forma está predestinado para cada un/unha de nós”).

Os Mitos restantes, o da Omnipotencia ("O amor verdadeiro pódeo todo") e a Equivalencia ("Se nunha relación de parella un/unha descubre que xa non sinte a paixón dos primeiros tempos, o mellor é abandonar a relación”), acadan nesta investigación puntuacións moi semellantes tanto en relación á aceptación como ao rexeitamento, en torno ao $30-35 \%$ en ámbolos dous casos.

Os resultados apoian a existencia dunha asociación significativa $(\mathrm{p}<.05)$ entre a variable Sexo e o Mito da Equivalencia (X2=12,540; $\mathrm{p}=0,028)$. Así mesmo, atopamos diferenzas significativas entre a variable Curso e os Mitos da Equivalencia (X2=12,503; $\mathrm{p}=0,029)$, a Omnipotencia $(\mathrm{X} 2=10,777 ; \mathrm{p}=0,029)$ e os Celos (X2=15,999; $\mathrm{p}=0,003)$. Non se atoparon relacións significativas $(\mathrm{p}>.05)$ entre as variables relativas á existencia de Relación de Parella e os Mitos do Amor Romántico, nin entre estes e a Autoestima.

\section{Discusión}

Un repaso polas investigacións máis salientables neste eido amosan puntos en común pero tamén diferenzas con respecto aos resultados obtidos.

O resultado relativo ao Mito do Emparellamento, aceptado aquí cun 74,7\%, coincide co do CIS (1995), onde a porcentaxe se eleva ata o $95 \%$. Pola contra, o resto dos estudos atopados o sitúan entre os Mitos menos apoiados, acadando só o $30 \%$ na investigación de Larrañaga et al. (2012), ao igual que no de Ferrer, Bosch e Navarro (2010). Neste último, o ítem inverso respecto a esta crenza acada o 68\% de aceptación, o que supón un rexeitamento moi elevado. Igual puntuación consigue no traballo de Bosh et al (2007). Na tese doutoral de Da Silva (2014), onde realiza unha análise cualitativa da aceptación dos Mitos, medindo a súa aceptación a partir das veces que xurde nas conversas das persoas, aparece como un dos menos presentes.

O nivel de aceptación do Mito da Fidelidade, co $61,2 \%$, é superado polo resultado da enquisa do CIS (1995), onde acada o 82\%. No estudo cualitativo de Da Silva (2014), este Mito é o máis presente no discurso das persoas participantes, moi por riba de outros.

En relación ao Mito do Matrimonio, o resultado obtido, 49,5\%, é menor que nas demais investigacións, excepto na de Da Silva (2014), onde se sitúa na penúltima posición. Na do CIS (1995), a porcentaxe elévase ata o $85 \%$ mentres que na de Larrañaga et al. (2012) é do 61\%. O ítem, presentado inversamente, acada un rexeitamento do $70 \%$ nos estudos de de Bosh et al (2007) e Ferrer, Bosch e Navarro (2010), o que implica un considerable apoio a esta crenza.

Por outra banda, o Mito máis rexeitado, o dos Celos, co $75,7 \%$, acadou puntuacións similares ás do estudo de Ferrer, Bosch, Navarro e Ferreiro (2010), onde a porcentaxe de rexeitamento é do $70 \%$ aproximadamente, ao igual que no de Bosh et al. (2007) e Larrañaga et al. (2012). Por último, na investigación de Da Silva (2014) este Mito atópase na última posición en canto a frecuencia no discurso dos/as participantes. Estes datos difiren dos recollidos na enquisa do CIS (1995), onde o 70\% declaraba experimentar un nivel alto de celos.

O mito da Perdurabilidade ou Paixón Eterna foi rexeitado cun $67,9 \%$ na presente investigación, e cun 64\% na enquisa do CIS (1995). No caso da investigación de Larrañaga et al. (2012) é o Mito máis aceptado, cunha porcentaxe do $87 \%$. Nos estudos de Bosh et al (2007) e Ferrer, Bosch e Navarro (2010) tamén acada as porcentaxes máis altas, en torno ao 70\%. Pola contra, na investigación de Da Silva (2014), ocupa unha das posicións máis baixas, ao mesmo nivel que o do Emparellamento. 
O nivel de rexeitamento do Mito da Exclusividade é do $53,4 \%$, semellante ao acadado no estudo do CIS (1995), onde a porcentaxe é do 55\%. Rebate este resultado a recente investigación de Da Silva (2014), onde este Mito aparece nas últimas posicións, aínda que por riba de outros como o do Emparellamento, a Perdurabilidade e o Matrimonio.

As puntuacións relativas ao Mito da Media Laranxa, 41,7\% de desacordo, difiren das outras investigacións. Na do CIS (1995), a de Bosh et al. (2007) e de Ferrer, Bosch e Navarro (2010), acadaron porcentaxes en torno ao 50\%. A puntuación resulta ser moito máis elevada no estudo de Larrañaga et al. (2012), onde acada o 85\%. Os datos da tese de Da Silva (2014) estarían máis próximos aos aquí presentados, pois sitúa o Mito de Media Laranxa nas últimas posicións.

Os Mitos restantes, o da Omnipotencia e a Equivalencia, acadan nesta investigación puntuacións moi semellantes tanto en relación á aceptación como ao rexeitamento, en torno ao $30-35 \%$ en ámbolos dous casos.

Os resultados acadados noutras investigacións son ben diferentes. Así, respecto ao da Omnipotencia, en relación ao nivel de aceptación, na enquisa do CIS (1995) chega a ser do 75\%, mentres que no de Bosh et al. (2007) e Ferrer, Bosch e Navarro (2010) oscila entre o 60 e $70 \%$. A porcentaxe máis alta atópase no estudo de Larrañaga et al. (2012), sendo do 85\%. Da Silva (2014) o sitúa no punto intermedio da súa escala. En relación ao Mito da Equivalencia, no estudo do CIS (1995) acada o 45\% de apoio. Na tese de Da Silva esta crenza aparece como a segunda en presenza nas conversas das persoas participantes, e polo tanto, resulta un dos Mitos máis arraigados.

Atendendo aos obxectivos buscados nesta investigación conclúese que existe unha ampla Aceptación do Mitos do Amor Romántico, en tanto que seis dos nove contan cun nivel de apoio superior ao $30 \%$.

Ademais, existe asociación significativa entre a variable Sexo e o Mito da Equivalencia e entre a variable Curso e os Mitos da Equivalencia, Omnipotencia e os Celos, non así nos restantes.

Considerando os resultados obtidos, ponse de manifesto a necesidade de realizar unha intervención cuxo obxectivo sexa evitar as consecuencias que se derivan da Aceptación do Mitos do Amor Romántico, tendo en conta as variables que presentan asociación. Así mesmo, considérase pertinente incluír na formación académica de Traballo Social esta temática para que os/as futuros/as profesionais sexan conscientes das estruturas existentes e podan intervir sobre elas.

\section{Referencias}

Atienza, F., Balaguer, I. e Moreno, Y. (2000). Análisis de la dimensionalidad de la escala de autoestima de Rosenberg en una muestra de adolescentes valencianos. Revista de Psicología Universitas Tarraconensis, 22 (12), 29-42.

Barrón, A., Martínez-Íñigo, D., De Paúl, P. e Yela, C. (1999). Beliefs and romantic myths in Spain. The Spanish Journal of Psychology, 2 (1), 6473. Recuperado o 27 de xaneiro de 2014 de DIALNET, http://revistas.ucm.es/index.php/SJOP/ article/view/SJOP9999110064A/29540

Bosh, E., Ferrer, V., García, M., Ramis, M., Mais, M., Navarro, C. e Torres G. (2007). Del mito del amor romántico a la violencia contra las mujeres en la pareja. Madrid: Estudios e Investigaciones, Instituto de la Mujer. Recuperado o 9 de marzo do 2014 de http://centreantigona.uab.cat/izquierda/amor\% 20romantico\%20Esperanza\%20Bosch.pdf.

Castañón, B. (2012). Mitos y realidades acerca de la violencia de género: entre el amor y la dominación (Tesis doctoral, Universidad de León). Recuperada o 11 de febreiro de 2014 https://buleria.unileon.es/bitstream/handle/106 12/2210/tesis_30acbb.PDF?sequence $=1$

Centro de Investigaciones Sociológicas (CIS) (1995). Actitudes y conductas afectivas de los españoles en el plano afectivo. Datos de opinión, 7. Recuperado o 30 de outubro de 2013 de http://www.cis.es/cis/opencms/Archivos/Boletines/07/BDO_7_conductasafec tivas.html

Da Silva, V. (2014). Comportamiento amoroso de pareja: mitos y paradojas románticas: un estudio comparativo entre Brasil y España. (Tesis doctoral: Universidad Complutense de Madrid). Recuperado 21 de xuño de 2014 de http://eprints.ucm.es/25231/1/T35350.pdf

Ferrer, V., Bosch, E., Navarro, C. e Ferreiro Basurto, V. (2010). El mito romántico de los celos y su aceptación en la sociedad española actual. Apuntes de psicología, 28 (3), 391-402.

Ferrer, V., Bosch, E. e Navarro, C. (xullo, 2010). Los mitos románticos en España. Boletín de psicología, 99, 7-31.

Hernández, R., Fernández, C. e Baptista Lucio, P. (2007). Fundamentos de Metodología de la Investigación. Madrid: McGraw-Hill.

Larrañaga, E., Yubero, S. e Yubero, M. (2012). Influencia del género y del sexo en las actitudes sexuales de estudiantes universitarios españoles. Summa psicológica ust, 9 (2), 5-13. 


\section{FAMILIA, ESCUELA Y COMUNIDAD}

Moral, M. e Sirvent, C. (2008). Dependencias sentimentales o afectivas: etiología, clasificación e avaliación. Revista española de drogodependencias, 33 (2) , 150-167. Recuperado o 11 de febreiro de 2014 en http://www.aesed.com/descargas/revistas/v33n 2_2.pdf
Yela, C. (2000). El amor desde la psicología social. Ni tan libres ni tan racionales. Madrid: Pirámide. Yela, C., Sangrador, J. e Jiménez, F. (2003). Las dos caras del amor: funciones, mitos, paradojas y renuncias. En S. Worchel, Psicología Social (pp. 260-262). Madrid: Thomson. 